\title{
AS INQUIETAÇÕES DO ARTISTA-PROFESSOR ${ }^{1}$
}

\author{
Sandra Maria Correia Favero²
}

Palavras - chave: universidade; produção acadêmica; espaço/tempo; produção poética.

RESUMO: Este artigo apresenta o resultado de uma pesquisa que colocou como objetivo identificar a relevância do desenvolvimento da produção artística em paralelo à produção do professor. Como sustentação teórica encontra-se Edgar Morin em Introdução ao Pensamento Complexo, Pedro Georgen com o artigo Universidade em tempo de transformação e Edith Derdik com o livro Linha de horizonte: por uma poética do ato criador.

\section{A universidade e o seu objeto}

A organização - universidade é um grande sistema, encabeça o domínio e visa o objeto. Ao centro temos o sujeito, de um lado o artista e do outro o professor que integram o grande sistema.

Encontramo-nos em um ambiente regido por um sistema ${ }^{3}$ complexo onde homens e mulheres compõem um conjunto que atua segundo regras e processos estabelecidos objetivamente, entretanto, ocorre na relação de uns com os outros uma combinação permanente de estratégias afetivas pessoais, grupais e organizacionais que modelam esta organização, por mais que a meta seja como diz Pedro Georgen, $o$ conhecimento através da neutralidade, da universalidade e da impessoalidade.

Segundo Goergen ${ }^{4}$

Já a partir de Descartes a universidade se desenha como a universidade da razão instrumental. A universalidade do saber deve desembocar na universalidade do progresso. A transformação dos modos de produção e a transformação da ciência condicionam-se mutuamente e condicionam a universidade desde sua estrutura, razão epistêmica, sentido social. Esta universidade, sede do saber e promotora do progresso, é colocado sob o âmbito de influência da vontade de eficácia do poder político moderno. Já não busca verdades ahistóricas, originais e últimas, mas serve à criação de conhecimentos e técnicas destinadas a produzir. Torna-se uma instituição técnica a serviço do Estado, guiada pela estrela da narrativa do progresso que a modernidade desenhava como o caminho da humanidade.

Convivendo em um centro de artes dentro da universidade onde a objetividade está sempre forçada a abrir brechas para a subjetividade contida no processo educativo dos cursos proporcionados e que por assim se apresentarem direcionam para uma produção que não é aquela que traz lucros financeiros imediatos, somamos um outro sistema complexo que deve ser analisado pelas suas especificidades, distanciando-o um pouco dos moldes estabelecidos.

No nosso caso, as especificidades das artes plásticas incluem em seu currículo e na vivência artística e acadêmica entre os professores e seus alunos os demais conhecimentos excluídos do conhecer científico

\footnotetext{
Projeto de Pesquisa CEART/UDESC

2 Professora do Departamento de Artes Plásticas do Centro de Artes, Av. Madre Benvenuta, 1907- Itacorubi, CEP88.3500-01 Florianópolis

3 Sistema - baseado no que descreve Edgar Morin no seu livro Introdução ao pensamento complexo. Porto Alegre: Editora Sulina, 2005, p.19, é "associação combinatória de elementos diferentes".

4 GOERGEN, Pedro. Universidade em tempo de transformação. www.prg.unicamp.br/texto. Acesso em : 9fev2007.
}

DAPesquisa, Florianópolis, v.2, n.4, p. 297-302, 2007. 
instaurado por Descartes.

Para Morin'(2005),

Vivemos sob o império dos princípios de disjunção, de redução e de abstração cujo conjunto constitui o que chamo de 'paradigma de simplificação': Descartes formulou este paradigma essencial do Ocidente, ao separar o sujeito pensante (ego cogitans) e a coisa entendida (res extensa) isto é filosofia e ciência, e ao colocar como princípio de verdade as idéias 'claras e distintas', isto é, o próprio pensamento disjuntivo. Este paradigma, que controla a aventura do pensamento ocidental desde o século XVII, sem dúvida permitiu os maiores progressos ao conhecimento científico e à reflexão filosófica: suas conseqüências nocivas últimas só começaram a se revelar no século XX.

Essa disjunção de que fala Morin pode ser percebida nas entranhas do sistema acadêmico, na pressão por produção quantitativa e objetiva, mais a acelerada sobrecarga de atividades burocráticas que dia a dia são transferidas para os professores, que acabam por reduzir a dedicação necessária em sala de aula.

Necessita-se a participação do sujeito com ele mesmo em todo o transcorrer do processo educacional, uma vez que o nosso objeto está imerso na subjetividade individual, porém, não está sozinho, convive no coletivo o que gera a necessidade de se auto-organizar como pessoa, como artista, como pesquisador, levando ao que $\operatorname{Morin}^{6}(2005)$ escreve como uma misteriosa qualidade chamada consciência de si.

O artista - professor como um propositor, portador de uma necessidade de conhecer algo, que não deixa de ser conhecimento de si mesmo, cujo alcance está na consonância do coração com o intelecto. Um corpo criador / um corpo professor, no mesmo corpo. O corpo que para Edith Derdik ${ }^{7}(2001)$ é uma grande colagem que forma um todo íntegro, coerente, único, coeso, idealizando uma nostálgica experiência de equilíbrio, constitutivo na formação do sujeito. Formação esta que identifica o "ser artista" e oferece vantagens para momentos de conflito e apaziguamentos que também são estabelecidos em relações do ser institucional. Ao afastar-se da prática artística o artista - professor inibe o movimento criativo gerador de todo o processo pertinente ao ensino de arte.

Nestas condições estabelece-se o paradoxo. O artista professor encontra-se entre a complexidade do sistema acadêmico gerido pelos moldes cartesianos objetivos e por outro lado a complexidade do sistema artístico.

Realizou-se uma breve pesquisa com quatro professores, denominados A- B- C-D, atuantes nas áreas de licenciatura e bacharelado comprometidos com os aspectos problemáticos, destacados nesta pesquisa. A formulação das quatro perguntas voltou-se a questões paradoxais por compreender que, como explicado anteriormente, o nível acadêmico e o nível artístico não são excludentes, e mesmo sendo paradoxais situando-se em termos subjetivos e objetivos, proporcionam ao artista-professor, ao aluno e à organização que os abriga possibilidades de enriquecimento na área em questão.

Importa destacar as perguntas apresentadas e esclarecer que as respostas aqui apresentadas não se encontram na íntegra.

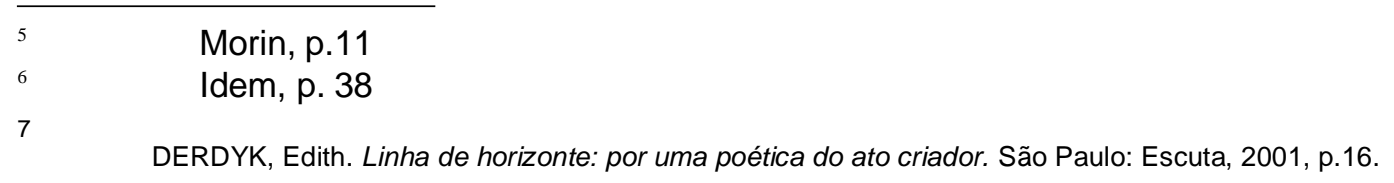


1) A prática do professor instiga a prática artística? Como se complementam?

2) Há disponibilidade de tempo/espaço para manter nutrida a produção poética dentro das exigências acadêmico-burocráticas?

3) Qual o sentido e como conduzem o problema: produção plástica e produção do professor (acadêmica)?

4) De que forma o pensamento e a produção acadêmica influência os ditames contemporâneos, ou é o contrário, os ditames contemporâneos influenciam a academia?

O Artista-Professor A preferiu não seguir a seqüência das perguntas e respondeu:

Bem, artista-professor... acho que um aspecto ajuda muito no outro. O fato de ser artista demanda um desenvolvimento do olhar muito intenso, que ajuda muito o professor a avaliar o que o aluno, individualmente, precisa desenvolver mais no trabalho e como; também completa a informação teórica com um corpo de experiência, dando a esta uma profundidade que ultrapassa a simples conceitualização.

Por outro lado o professor, com todo o seu instrumental de informação e de como compartilhá-la, traz para a experiência do artista uma dimensão de diálogo muito grande, de reflexão sobre o processo criativo de uma maneira mais ampla e também de sistematização destas experiências.

\section{Artista-Professor B}

1. Sim. Ela solicita uma maior clareza sobre os assuntos dos quais se está tratando, sobre o campo da arte e sobre seu próprio trabalho, e para isso, o estudo e a pesquisa são fundamentais. A pesquisa aparece então como tendo um papel importante a desempenhar nesse processo, pois ela tanto impulsiona esses aspectos a serem desenvolvidos durante a aula, como esclarece e impulsiona o que faço como artista...

...A prática do professor instiga o exercício do perguntar, tanto em relação a si mesmo como em relação aos estudantes, e instiga a fazer que isso também seja uma prática para eles

... Procuro manter o mais próximo possível a minha prática de professor da minha prática artística.

2. ...A universidade seguidamente comporta-se de uma maneira bastante ambígua no que diz respeito ao campo da arte. Por um lado ela propicia e mantém aberto um espaço fantástico de criação, discussão e estudo da arte, o que lhe dá uma grande visibilidade (vide o que sai nos jornais). Por outro lado, esse espaço da arte na universidade poderia ser melhor se houvesse um incremento de verbas, espaço físico, equipamentos, funcionários qualificados. A burocracia administrativa universitária é ainda muito pesada, e pouco sensível em relação à área artística.

3. Foi a produção artística que me encorajou a pensar que poderia ser professor... Atualmente, a atividade artística é o que continua a impulsionar meu trabalho como professor, embora essa atividade experimente mudanças em sua concepção. Para mim não haveria sentido em minha produção como professor sem uma produção artística e sem uma relação com o campo artístico (relação nem sempre fácil), pois é onde se pode encontrar na prática discussões sobre as concepções mesmas dessa prática.... A arte é um exercício DAPesquisa, Florianópolis, v.2, n.4, p. 297-302, 2007. 
constante...

4.A universidade influencia bastante no perfil dos novos artistas e em seu conhecimento, bem como abre espaço para experimentações, produções e reflexões que não teriam vez em outros setores do campo artístico como galerias (mercado) ou museus. Por outro lado, alguns setores dentro da universidade são pouco críticos (embora tenham cultura e conhecimento para isso) e muito sensíveis ao que o mercado de arte e a mídia arbitrariamente valorizam e instauram como modelos.

\section{Artista-Professor C}

1. Para mim, as práticas do professor-artista/artista-professor são indissociáveis, na medida em que uma abastece, amplia e amplifica a outra. Penso que essa situação de retro-alimentação é complexa e sutil, móvel e instável. Catalisar e mediar processos artísticos, investigando artistas, procedimentos no campo da arte e de outros campos de saber, dialogando com outras experiências, vivências e conceitos, bem como, agenciar eventos artísticos coletivos e desenvolver pesquisas teóricas e práticas em arte, constituem exercícios totalmente complementares e coextensivos à minha prática artística.

2. Talvez esta seja uma das questões a serem repensadas no contexto da academia: como e o quê fazer para coincidir cada vez mais as práticas do professor-artista/artista-professor, onde o mesmo possa produzirpesquisar, ao mesmo tempo, artisticamente e academicamente? Como reduzir o peso das atividades administrativas dentro do cotidiano do professor-artista?

3. Penso que minhas práticas de professora-artista/artista-professora são indissociáveis, onde uma abastece, amplia e amplifica a outra, de um modo móvel e instável Minhas atividades de Ensino, Pesquisa e Extensão implicam, de maneiras diferenciadas, minha própria produção artística.

... Ou seja, produzir arte significa construir conhecimento, de forma prática e teórica, onde processos ou investigações artísticas desdobram-se em reflexões e vice-versa. Deste modo, produzir academicamente e artisticamente co-implicam-se.

4. Apesar desta ser uma questão extremamente complexa, uma situação interessante e instigante seria a de uma intensa reciprocidade entre o pensamento produzido na universidade e o contexto contemporâneo... Penso ser urgente ampliar, fomentar e discutir a difusão do pensamento produzido na academia no contexto artístico contemporâneo. Uma destas maneiras consiste em discutir exatamente a questão colocada nas perguntas e respostas anteriores: como diminuir a distância, nas atividades de Ensino, Pesquisa e Extensão, entre nossa produção artística e nossa atuação como professores?

\section{Artista-Professor D}

DAPesquisa, Florianópolis, v.2, n.4, p. 297-302, 2007. 
1. Se eu for considerar o modo trabalho em minhas disciplinas posso dizer que esta prática influenciou muito os meus projetos pessoais. Fui dar aulas na escultura e fiz deste desafio uma forma de questionamento constante. Sempre discutimos em aula o que seria enfocado e a forma de trabalhar os assuntos da arte com os meus alunos. Aprendi muito com eles.

2. Eu tenho vivenciado este problema com certo jogo de cintura, na medida em que faço com que a minha produção plástica integre os meus projetos de pesquisa e extensão cadastrados como tal junto ao Departamento e Unidade... A burocracia toma muito do meu precioso tempo de trabalho prático...Por outro lado acho que estamos avançando muito, vendo a situação da arte no Brasil, e aposto no entendimento da relação produção-pesquisa... Vemos que não é mais possivel sustentar a idéia romântica da criação artística desvinculada de qualquer problema (eles sempre existiram). Hoje somos mais conscientes e a cada vez mais confrontados com os problemas de contexto e estes passam a entrar no nosso horizonte criativo tencionando-o.

3. Para mim este é um caminho de mão dupla... A produção artística desvenda um contexto e também tenciona os modos de visualidade definindo as políticas do visível. Por outro lado a exposição torna-se o laboratório onde é possível confrontar-se com o campo da arte e que nos conduz por conseqüência ao trabalho reflexivo, abrindo perspectivas autocríticas que esclarecem e ampliam também o entendimento do público... Um artista/professor/pesquisador tem muito poder transformador em suas mãos, pois exercita e exerce de forma integrada os distintos papéis: influencia o seu público, altera o seu meio e propõe principalmente outras formas de ver e de viver com a arte...

4. Acho que a arte contemporânea é para muitos um negócio, para alguns uma paixão e para a maioria uma condição na qual não lhes é dada opção de escolha... A arte irá para onde a levarmos A universidade aí se incluiu com seu peso considerável (que depende do time), e pode levar em conta e refletir sobre a grande dose de informalidade na qual se encontra a sociedade contemporânea. Existe uma grande força "fora da ordem" que gera visualidade e crítica e que tenciona de forma efetiva o campo da arte contemporânea (brasileira). Teríamos muitos exemplos na atualidade, assunto que mereceria ser analisado. Destaco o conhecimento que se produz seriamente fora da academia e que pode entrar na pauta do conhecimento...

\section{Considerações Finais}

Considera-se que a posição do artista-professor consciente é privilegiada dentro do quadro organizacional da universidade. Ele amplia seus conhecimentos, integra suas ações: Produção Artística Ensino - Pesquisa - Extensão; gerencia paradoxos focando uma constante busca de conhecimento que entrelaça as convergências com as divergências que surgem durante as suas ações; é estimulado e estimula o processo contínuo de ordenamento e desordenamento da posição artística e acadêmica fortalecendo seu

DAPesquisa, Florianópolis, v.2, n.4, p. 297-302, 2007. 
posicionamento diante do aluno, da organização e da sociedade em que está inserido.

A complexidade do sistema de artes reforça a necessidade de um artista-professor responsável e consciente da sua posição de construtor de conhecimento em arte que é ao mesmo tempo propositor, formador e crítico reflexivo que tem sua conduta baseada na atuação prática e teórica. Este posicionamento dentro da universidade implica em desdobramentos de ações externas a ela que poderão contribuir para um melhor entendimento do que vem a ser arte contemporânea.

Por ser a universidade uma organização complexa que propicia momentos experimentais que estimulam a criação e a reflexão, reafirma-se a necessidade de estreitamento cada vez maior entre os três braços por ela oferecidos - Ensino - Pesquisa - Extensão, para que o alcance dessa produção acadêmica venha a partilhar com o contexto artístico distanciado dela. O artista-professor é o fio condutor deste caminho.

\section{Referências Bibliográficas}

DERDYK, Edith. Linha de horizonte: por uma poética do ato criador. São Paulo: Escuta, 2001. GEORGEN, Pedro. Universidade em tempo de transformação. www.prg.unicamp.br/texto. Acesso em : 9fev2007.

MORIN, Edgar. Introdução ao pensamento complexo. Porto Alegre: Editora Sulina, 2005.

SALLES, Cecília Almeida. Gesto Inacabado: processo de criação artística. São Paulo: FAPESP: Annablume, 1998. 